\section{Discussion}

The innominate artery is the second most common site of blunt injury to the aortic vessels, and blunt trauma is responsible for $35 \%$ of innominate artery injuries. ${ }^{1}$ Still, fewer than 100 cases of innominate artery injury caused by blunt trauma have been documented. ${ }^{2-4}$ An interesting association has been reported between this type of injury and bovine arch anatomy, in which the left common carotid originates from the innominate artery. Although there is only an $11 \%$ normal incidence of bovine arch anatomy, $29 \%$ of patients who have innominate artery disruption exhibit this anomaly, suggesting a predisposition to sustaining blunt injury at the innominate artery. ${ }^{1}$

One study recommended bypass of the injured segments of the arch before exploring the hematoma. ${ }^{4}$ This patient was placed on cardiopulmonary bypass before dissection of the hematoma. Cardiopulmonary bypass allows for greater visualization of the arch by decompressing the heart and provides more hemodynamic control. The risk of systemic anticoagulation in the setting of a grade III liver laceration and femur fracture did not escape us, and measures were taken to reduce the patient's risk by placement of an external fixator on the femur and by aggressive surveillance to detect early intraperitoneal bleeding. ${ }^{4}$

Because repair of this injury would likely disrupt most of the cerebral blood flow, the issue of cerebral perfusion had to be addressed. In this particular patient, retrograde cerebral perfusion was used in conjunction with deep hypothermia and circulatory arrest. Our center has had extensive experience with this technique in repair of complex arch reconstructions and acute type A dissections. Despite recent reports suggesting that retrograde cerebral perfusion may be linked to postoperative neurologic dysfunction, our experience is that the incidence of perioperative stroke is reduced. ${ }^{5}$ In addition, retrograde cerebral perfusion also extends greater latitude in operating time and cools the brain down roughly an additional $10^{\circ} \mathrm{C} .{ }^{5}$ Finally, it provides a deairing capacity by continually bathing the cerebral vascular system in blood. ${ }^{5}$

\section{References}

1. Graham JM, Feliciano DV, Mattox KL, Beall AC. Innominate vascular injury. J Trauma. 1982;22:647-55.

2. Johnson RH, Wall MJ, Mattox KL. Innominate artery trauma: a thirty year experience. J Vasc Surg. 1993;17:134-40.

3. Mauney MM, Casada DC, Kaza AK, Long SM, Kern JA. Management of innominate artery injury in the setting of bovine arch anomaly. Ann Thorac Surg. 2001;72:2134-6.

4. Jweied E, Fogelson B, Fishman D, Merlotti G. Blunt injury of the innominate artery associated with a bovine arch. J Trauma. 2002;52:1002-4.

5. Pochettino A, Cheung AT. Pro: retrograde cerebral perfusion is useful for deep hypothermic circulatory arrest. J Cardiothorac Vasc Anesth. 2003; 17:764-7.

\title{
Distal aortic arch aneurysm after endovascular stent graft repair for type B chronic aortic dissection
}

\author{
Claudio F. Russo, MD, Andrea Garatti, MD, Maurizio Puttini, MD, and Ettore Vitali, MD, Milan, Italy
}

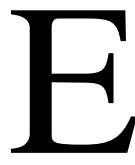

ndovascular stent grafting of the descending thoracic aorta has recently become a valid and safe alternative to surgical treatment of type B aortic dissection, even though it has been related to some complications, such as graft displacement, aortic injury, paraplegia, embolization, stroke, and left arm ischemia. In these cases, surgical management can be troublesome, particularly when displacement of the graft and proximal endoleak involve the aortic arch or the origin of the supra-aortic vessels.

\footnotetext{
From the Department of Cardiovascular Surgery, "A. De Gasperis,” Niguarda Ca'Granda Hospital, Milan, Italy.

Received for publication Jan 9, 2004; revisions requested Feb 5, 2004; revisions received Feb 12, 2004; accepted for publication March 16, 2004

Address for reprints: Andrea Garatti, MD, Department of Cardio-Thoracic Surgery, “A. De Gasperis," Ospedale Niguarda Ca'Granda, Piazza Ospedale Maggiore 3, 20162 Milan, Italy (E-mail: agaratti@tiscali.it).

J Thorac Cardiovasc Surg 2004;128:634-6

$0022-5223 / \$ 30.00$

Copyright $\odot 2004$ by The American Association for Thoracic Surgery

doi:10.1016/j.jtcvs.2004.02.035
}

\section{Clinical Summary}

A 68-year-old man came to the emergency room with cramplike pain in his right leg. He was obese and a heavy smoker, with a history of high blood pressure and mild chronic renal failure. General examination was unremarkable. Computed tomographic (CT) scan showed an extensive chronic type B aortic dissection with an aortic diameter greater than $6 \mathrm{~cm}$. Transesophageal echocardiogram confirmed the diagnosis and showed a wide intimal tear with no involvement of the left subclavian artery. Because of stable conditions and the lack of complications, the patient did not undergo urgent surgery but was managed medically. At aortography, aortic dissection extended from the distal aortic arch to the femoral vessels; all visceral branches arose from the true lumen, but both superior mesenteric and left renal arteries were partially compressed by the false lumen. An anomalous origin of the supraaortic vessel was detected with a common origin of the left carotid and subclavian arteries (left brachiocephalic trunk). Considering the large dimension of the thoracic aorta and the risk of visceral vessel malperfusion, the patient underwent successful endovascular exclusion of the intimal tear with a Thoracic Excluder (W. L. Gore \& Associates, Inc, Flagstaff, Ariz; $40 \mathrm{~mm} \times 15 \mathrm{~cm}$ ). The stent graft was placed distally from the origin of the arch vessels. 
Angiography showed good results of the procedure, without signs of endoleak or malperfusion of the arch vessels. At the 2-month follow-up, there was evidence of proximal endoleak due to endovascular graft displacement, with persistence of blood flow in the false lumen and rapid development of a giant thoracic aneurysm with compression of the left carotid and subclavian arteries. A CT scan (Figure 1) of the chest showed a 13-cm aneurysm of the upper descending aorta, with a soft tissue mass abutting the aneurysm and extravasation of contrast material between the stent graft itself and the aneurysmal aortic wall. Because of proximal displacement deep in the aortic arch, the stent graft completely covered the common ostium of the left common carotid and subclavian arteries. Percutaneous endoprosthesis dilation was unsuccessful. Elective surgical aneurysm resection and aortic arch reconstruction was then planned. The operation was performed through a median sternotomy; cannulation of both venae cavae and the ascending aorta was achieved, cardiopulmonary bypass was instituted, and systemic cooling was started. During cooling, the left brachiocephalic trunk was detached from the aortic arch and sutured terminolaterally on the innominate artery. Deep hypothermic circulatory arrest was achieved at $16^{\circ} \mathrm{C}$ with retrograde perfusion of the brain through the superior caval vein. Myocardial protection was maintained with intermittent retrograde cold blood cardioplegia. The distal ascending aorta was then opened; the endovascular graft had moved proximally into the aortic arch and was actually covering the common ostium of the left carotid and subclavian arteries and almost reaching the origin of the innominate artery. No displacement of the stent was attempted, because we considered this maneuver highly hazardous. A woven vascular prothesis (No. 34; Sulzer Vascutek, Renfrewshire, United Kingdom) was then implanted to replace the aortic arch with total exclusion of the supra-aortic vessel with the elephant trunk technique. The proximal end was anastomosed to the distal ascending aorta. The elephant trunk graft extended into the endovascular stent and descending aorta for $10 \mathrm{~cm}$, leading to obliteration of the endoleak. Finally, a Dacron graft (DuPont, Wilmington, Del) was interposed to anastomose the innominate artery on the proximal ascending aorta. The postoperative course was uneventful, and the patient was discharged home in good condition. At the 6-month followup, a CT scan confirmed good operative results (Figure 2).

\section{Discussion}

Most Stanford type B acute dissections can be managed medically. ${ }^{1}$ However, in complicated type B acute dissections-such as those with rupture, impending rupture, or end-organ ischemiasurgery is mandatory. Moreover, aneurysmal enlargement in the chronic phase of dissection is another concern because it necessitates the use of extended graft replacements for thoracic and thoracoabdominal lesions. Operative results of these procedures have improved markedly, but mortality and morbidity remain high because patients with aortic aneurysms are often elderly and frequently have various comorbidities. ${ }^{2}$ However, for acute disease complicated by end-organ ischemia, the operative mortality rate exceeds $50 \% .^{3}$ Endoluminal aortic stent graft placement has recently been introduced for repair of abdominal and thoracic aneurysm, but endoluminal repair is also now reported as a promising therapeutic strategy in high-risk settings such as aortic dissections. Some complications, such as graft displacement, aortic injury,

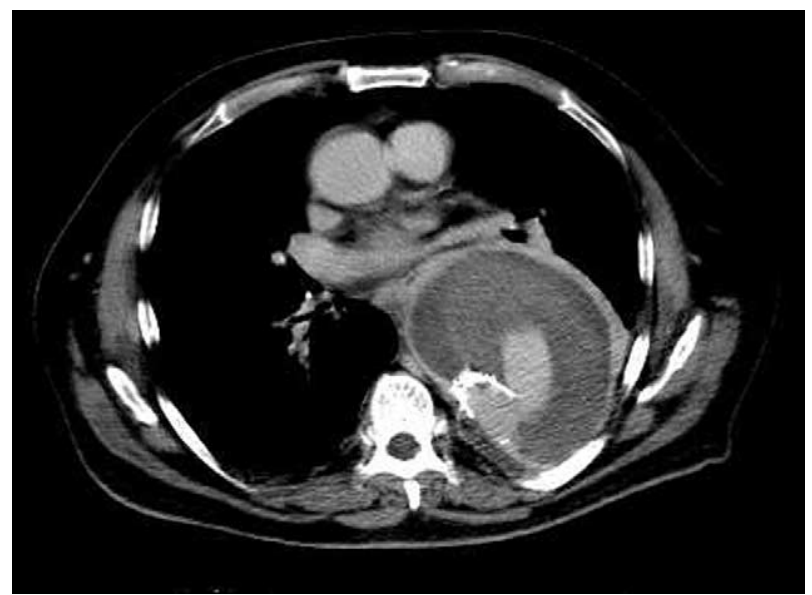

Figure 1. Preoperative computed tomographic scan showing the aneurysm of the thoracic descending aorta with extravasation of contrast between the stent graft itself and the aneurysmal aortic wall.

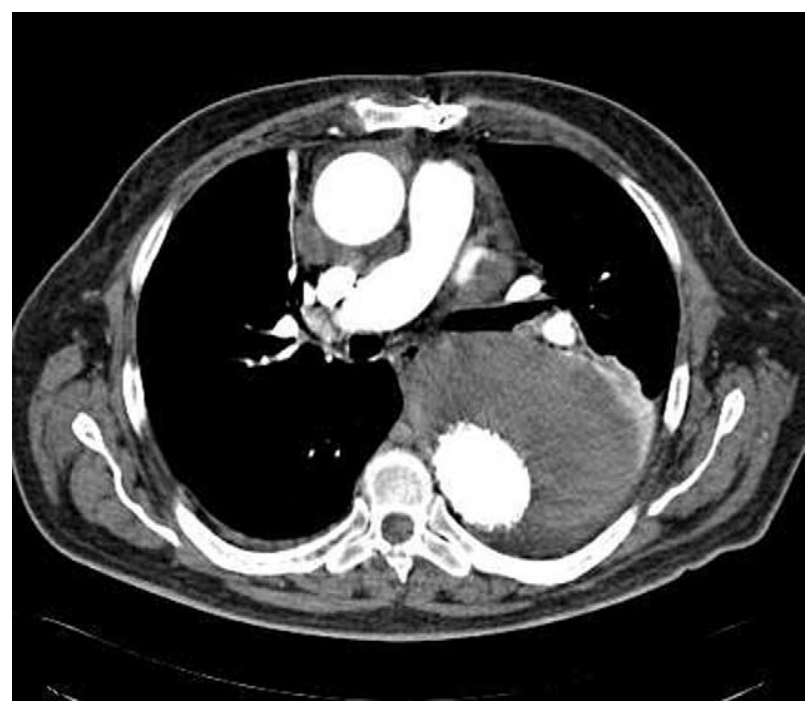

Figure 2. Computed tomographic scan at the 6-month follow-up, showing good operative results; there is no evidence of residual flow in the false lumen.

paraplegia, embolization, stroke, and left arm ischemia, could be associated with this technique. It is important to note that in the acute setting, the stent graft-related rate of complications is nearly $50 \%$, and endoleak is the most common early complication in $24 \%$ of patients. ${ }^{4}$ The clinical results of stent grafting for chronic dissection are also acceptable in many reported experiences. ${ }^{5}$ Shimono and colleagues ${ }^{6}$ reported no deaths or ruptures in their series of 37 consecutive patients; the primary entry site was sealed, and thrombosis of the false lumen in the thoracic aorta was accomplished in all patients. The size of false lumen was not decreased in $18 \%$ of chronic dissections, as determined by the follow-up CT, and the incidence of progressive enlargement of the 
false lumen abruptly increased (62\% to $82 \%$ ) in case of thoracic or thoracoabdominal aneurysm at the moment of dissection. The concept of endotension because of unobservable endoleak and pressure transmittance through the thrombus has recently been suggested as a cause of this phenomenon. ${ }^{7}$ Leaks may also occur at the ends of the stent graft or may result from retrograde filling from an aortic branch. Finally, extension and quality of landing zone are very important issues to prevent endoleak. Because many type $\mathrm{B}$ aortic dissections have primary entry tears cross to the orifice of the left subclavian artery, bending of the stent graft at the small curvature of the aortic arch shows a high risk of endoleak or retrograde dissection. From a surgeon's point of view, it is important to know that an acute retrograde aortic dissection after an initial type B dissection may occur during, shortly after, or even late after an implantation of an endovascular stent graft. Surgical treatment in this setting crucially depends on the anatomic location of the endovascular stent in relation to the aortic arch and arch vessels. The elephant trunk procedure seems to be particularly useful in this type of dissection. ${ }^{8}$ In conclusion, endovascular treatment of aortic aneurysms and dissection is an effective and promising option, but technical improvements and better patient selection are mandatory to avoid dangerous complications necessitating high-risk surgery.

\section{References}

1. Elefteriades JA, Hartleroad J, Gusberg RJ. Long-term experience with descending aortic dissection: the complication specific approach. Ann Thorac Surg. 1992;53:11-21.

2. Coselli JS, Lemaire SA, Miller CC. Mortality and paraplegia after thoracoabdominal aneurysm repair: a risk factor analysis. Ann Thorac Surg. 2000;69:409-14.

3. Svensson LG, Crawford ES, Hess KR. Experience with 1509 patients undergoing thoracoabdominal aortic operations. J Vasc Surg. 1993;17: 357-63.

4. Dake MD, Kato N, Mitchell RS. Endovascular stent-graft placement for the treatment of acute aortic dissection. N Engl J Med. 1999;340:154652.

5. Nienaber CA, Fattori R, Lund G, et al. Non surgical reconstruction of thoracic aortic dissection by stent-graft placement. $N$ Engl $\mathrm{J} \mathrm{Med.}$ 1999;340:1539-45.

6. Shimono T, Kato N, Yasuda F, et al. Transluminal stent-graft placements for the treatments of acute onset and chronic aortic dissections. Circulation. 2002;106(suppl 1):I241-7.

7. Gilling-Smith G, Brennan J, Harris P. Endotension after endovascular aneurysm repair: definition, classification, and strategies for surveillance and intervention. J Endovasc Surg. 1999;6:305-7.

8. Totaro M, Miraldi F, Fanelli F, Mazzesi G. Emergency surgery for retrograde extension of type B dissection after endovascular stent graft repair. Eur J Cardiothorac Surg. 2001;20:1057-8.

\title{
Venous embolization during sternotomy in children undergoing corrective heart surgery
}

\author{
Ilan Keidan, MD, ${ }^{\text {a }}$ Yael Mardor, PhD, ${ }^{\mathrm{b}}$ Sergei Preisman, MD, ${ }^{\mathrm{a}}$ and David Mishaly, MD, ${ }^{\mathrm{c}}$ Tel Aviv, Israel
}

$\mathrm{G}$ as embolism results from a negative pressure gradient between veins exposed to air and the central venous pressure. ${ }^{1}$ The incidence varies according to the procedure, the position, and the detection method used. Venous air embolism (VAE) in cardiac surgery has been previously observed during central venous cannulation and while opening the heart chambers during cardiopulmonary bypass. ${ }^{2}$ We now describe, for the first time, the detection of VAE by transesophageal echocardiography during sternotomy in children undergoing

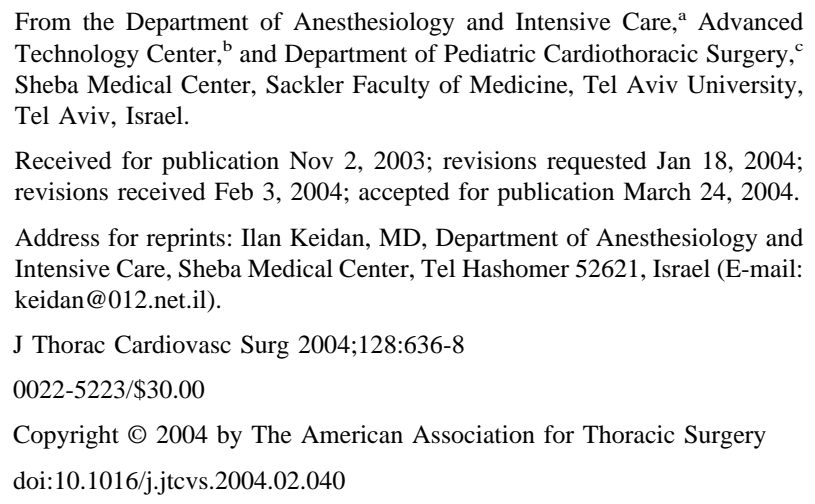

Received for publication Nov 2, 2003; revisions requested Jan 18, 2004; revisions received Feb 3, 2004; accepted for publication March 24, 2004.

Address for reprints: Ilan Keidan, MD, Department of Anesthesiology and Intensive Care, Sheba Medical Center, Tel Hashomer 52621, Israel (E-mail: keidan@012.net.il).

J Thorac Cardiovasc Surg 2004;128:636-8

$0022-5223 / \$ 30.00$

Copyright $\odot 2004$ by The American Association for Thoracic Surgery

doi:10.1016/j.jtcvs.2004.02.040

corrective heart surgery. In addition, we show that sternotomy with scissors significantly reduces the risk of embolization compared with using a saw.

\section{Patients and Methods \\ Patients}

Twenty children scheduled for corrective heart surgery were enrolled. Patients with a previous sternotomy were excluded. Patients were randomly assigned to the saw or scissors group. Ten children who underwent sternotomy with a saw had a ventricular septal defect $(n=2)$, total anomalous pulmonary venous return $(n=1)$, tetralogy of Fallot $(n=1)$, truncus arteriosus $(n=1)$, mitral stenosis $(n=1)$, or double-outlet right ventricle $(n=1)$. The other 10 children who underwent sternotomy with scissors had an atrial septal defect $(n=2)$, ventricular septal defect $(n=2)$, tetralogy of Fallot $(n=2)$, total anomalous pulmonary venous return $(n=1)$, hypoplastic left heart syndrome $(n=1)$, transposition of the great arteries $(\mathrm{n}=1)$, and cor triatriatum $(\mathrm{n}=1)$.

\section{Monitoring}

Monitoring included electrocardiogram, pulse oximetry, end-tidal carbon dioxide, invasive arterial blood pressure, and central venous pressure. During sternotomy, patients were disconnected from the ventilator, and no fluids or medications were infused. 